\title{
Air pollutant emission factors from new and in-use motorcycles
}

\author{
Jiun-Horng Tsai ${ }^{\mathrm{a}, *}$, Yih-Chyun Hsu ${ }^{\mathrm{a}}$, Hung-Cheng Wenga, \\ Wen-Yinn Lin ${ }^{\mathrm{b}}$, Fu-Tien Jeng ${ }^{\mathrm{c}}$ \\ ${ }^{a}$ Department of Environmental Engineering, National Cheng-Kung University, Tainan, Taiwan \\ ${ }^{\mathrm{b}}$ Department of Environmental Engineering, Kung Shan Institute of Technology, Tainan, Taiwan \\ ${ }^{\mathrm{c}}$ Graduate Institute of Environmental Engineering, National Taiwan University, Taipei, Taiwan
}

Received 7 December 1999; received in revised form 29 April 2000; accepted 10 May 2000

\begin{abstract}
The emissions of carbon monoxide (CO), nitrogen oxides $\left(\mathrm{NO}_{x}\right)$ and total hydrocarbon (THC) from 7 new and 12 in-use motorcycles with or without the catalyst were evaluated by testing these vehicles on a dynamometer. Also the concentrations of volatile organic compounds (VOCs) in five driving patterns, including idle, acceleration, $30 \mathrm{~km} \mathrm{~h}^{-1}$ cruise, $50 \mathrm{~km} \mathrm{~h}^{-1}$ cruise, and deceleration, were monitored.Experimental results indicate that the emissions of CO and THC from in-use motorcycles are significantly higher than new ones, but not for $\mathrm{NO}_{x}$, and the emissions of THC from 2-stroke motorcycles are much higher than 4-stroke ones. The emissions of VOCs from in-use motorcycles are higher than new motorcycles for all five driving patterns, and those from 2-stroke engines are higher than 4-stroke motorcycles. Emission of VOCs in the modes of deceleration and idle accounts for the most mass emitted during the test driving cycle. (C) 2000 Elsevier Science Ltd. All rights reserved.
\end{abstract}

Keywords: Motorcycle; Dynamometer; Volatile organic compound; Driving pattern; Emission factor

\section{Introduction}

Taiwan has had significant air pollution problems accompanied with the rapid economic development since 1970s. A great number of motor vehicles, including passenger cars, buses, and motorcycles, route around the island and exhibit serious air pollution problems both in urban areas and suburban regions. There are about 16 million motor vehicles in Taiwan, with about $66 \%$ motorcycles, $32 \%$ gasoline passenger cars, and $1 \%$ of diesel trucks and buses (MOT, 1998). These vehicles contribute a greater portion of air pollutant emissions. For example, in 1995 the emissions of carbon monoxide $(\mathrm{CO})$, nitrogen oxide $\left(\mathrm{NO}_{x}\right)$, non-methane hydrocarbon (NMHC), and particulate matters (PM) were estimated to be $1720,420,840$, and 530 thousand metric tons, respectively, in Taiwan (TEPA, 1997). Meanwhile, the mobile emissions accounted for $83 \%$ of $\mathrm{CO}, 49 \%$ of

\footnotetext{
${ }^{*}$ Corresponding author. Fax: + 886-6-275-2790.
}

$\mathrm{NO}_{x}, 33 \%$ of $\mathrm{NMHC}$, and $9 \%$ of PM in the inventory. The detailed source profiles of various mobile emissions further indicated that $38 \%$ of $\mathrm{CO}, 3 \%$ of $\mathrm{NO}_{x}, 64 \%$ of NMHC, and $30 \%$ of PM were released from motorcycles (TEPA, 1998). Because of their mobility and convenience, motorcycles are extremely popular in both urban and rural areas in Taiwan and some other countries in Southeast Asian, and the quantity of motorcycles is expected to increase in the future. The main type of motorcycles in Taiwan is 2 -stroke engine with $61 \%$, and the other is 4-stroke engine.

In order to improve the air quality, the Taiwan Environment Protection Administration has declared a policy to minimize the emissions from major sources. However, a more accurate emission inventory is necessary for successful strategy and implementation. For instance, when considering whether to give priority to phase-out of the 2-stroke engine motorcycles, is it definitely needed to understand the source profile, emission rate, and source inventory? Although some researches about control programs for motorcycle emissions have been reported, only few studies focus on motorcycle emissions (Chan et al., 
1995; Tsai et al., 1997). Consequently, this study was undertaken to assess the engine exhaust of $\mathrm{CO}$, THC and $\mathrm{NO}_{x}$, from both new and in-use motorcycles. Emission tests were conducted on a dynamometer following the designated test procedure similar to that of the Economic Commission for Europe (ECE). The effects of engine types (2- and 4-stroke), mileage, and installation of the catalyst on the emission were evaluated.

\section{Methods and materials}

\subsection{Selection of motorcycles}

Test motorcycles were selected according to the engine type, installation of the catalyst or not, and mileage of in-use motorcycles in southern Taiwan. There were 19 motorcycles tested in this study, including 7 new and 12 in-use motorcycles. The later consisted of eight 2-stroke and four 4-stroke engines, while the former of four 2 -stroke and three 4-stroke engines.

The new motorcycles were supplied by a manufacture plant and were ready for sell. All these new motorcycles must comply with EPA's emission standard. The in-use motorcycles tested in this study were selected from a service center of in-use motorcycles. These in-use motorcycles were chosen mainly considering theirs accumulated running mileage. Unlike new motorcycles, tested in-use motorcycles did not necessarily comply with the emission standard, though the in-use motorcycle emission standard is quite loose.

According to the engine types (2- and 4-stroke), running mileage (new, in-use) and the condition of catalyst (with and without), the tested motorcycles were divided into five groups (as shown in Table 1): 2-stroke-new-w-catalyst, 4-stroke-new-w/o-catalyst, 2stroke-in-use-w-catalyst, 2-stroke-in-use-w/o-catalyst, and 4-stroke-in-use-no-catalyst. The oldest motorcycle tested in this study was produced in 1982.

\subsection{Selection of testing cycle}

The driving patterns of vehicles in the metropolitan areas in Taiwan are similar to those of ECE cycle, which is adopted as the test standard consequently (TEPA, 1996). One complete test cycle (780 s) includes idle (240 s), acceleration (168s), cruising (228s), and deceleration (144s), and four different cruising speeds are applied in the tests: $15,32,35$, and $50 \mathrm{~km} \mathrm{~h}^{-1}$. Fig. 1 shows the driving pattern of testing cycle.

\subsection{Dynamometer testing}

The dynamometer used in this study is located in a certified laboratory of a motorcycle manufacture plant.
Table 1

Conditions of tested motorcycle

\begin{tabular}{lllc}
\hline Classification & & Number & $\begin{array}{c}\text { Mileage } \\
\left(10^{3} \mathrm{~km}\right)\end{array}$ \\
\hline \multirow{3}{*}{-stroke } & New-w-catalyst & 4 & \\
& In-use-w-catalyst & 5 & $3.1-34.1$ \\
4-stroke & In-use-w/o-catalyst & 3 & $43.4-210$ \\
& New-w/o-catalyst & 3 & \\
& In-use-w/o-catalyst & 4 & $10.8-41.4$
\end{tabular}

Tested motorcycles were examined first for safety and replaced fuel to make sure that no additives in the fuel. Overnight, after preliminary examination, tested motorcycles were warmed up before running the driving cycles on the dynamometer. Each motorcycle was tested once for whole cycles. Fig. 2 indicates the flow scheme of dynamometer testing and gas sampling.

\subsection{Gas sampling and analysis}

Two types of samples were collected in each test. One was for the entire cycle with an automated instrument for $\mathrm{CO}, \mathrm{NO}_{x}$, and THC measurements, and the other was for stage emissions under different driving patterns for hydrocarbon speciation. The tailpipe of motorcycles was directly connected to a sampling system under testing conditions of the entire cycle. Exhaust gas was emitted to a constant volume system (chamber) and diluted using indoor air, then was leaded into sampling bags and analyzed for $\mathrm{CO}$, THC, and $\mathrm{NO}_{x}$ by monitors (HORIBA, MEXA-8320). The background concentrations of indoor air were also analyzed routinely and deducted from the test results. Background concentrations for $\mathrm{CO}, \mathrm{THC}$, and $\mathrm{NO}_{x}$ were about 2, $6 \mathrm{ppm} \mathrm{C}$, and $0.1 \mathrm{ppm}$, respectively, and were much lower than sampled gases.

For different driving pattern sampling, five vacuum boxes were applied to contain various gas samples, and each vacuum box contained a 3-1 Tedlar bag. Exhaust gas was diluted using room ambient air pumped with a controlled flowrate. Several control valves were used to guide samples of different driving patterns into various designated Tedlar bags. Due to the limitation of available facility, the sampling work was conducted manually. After samples were taken, the bags were placed into a black container and carried to the analysis laboratory for hydrocarbon species analysis within $4 \mathrm{~h}$. Background samples from the room air in the dynamometer laboratory were also recorded.

In the analysis laboratory, hydrocarbon species in the sample bags were preconcentrated by a purge and trap system (AERO Trap Desorber, Tekmar 6000) and then analyzed by a GC/MS (Hewlett Packard 5890II \& 


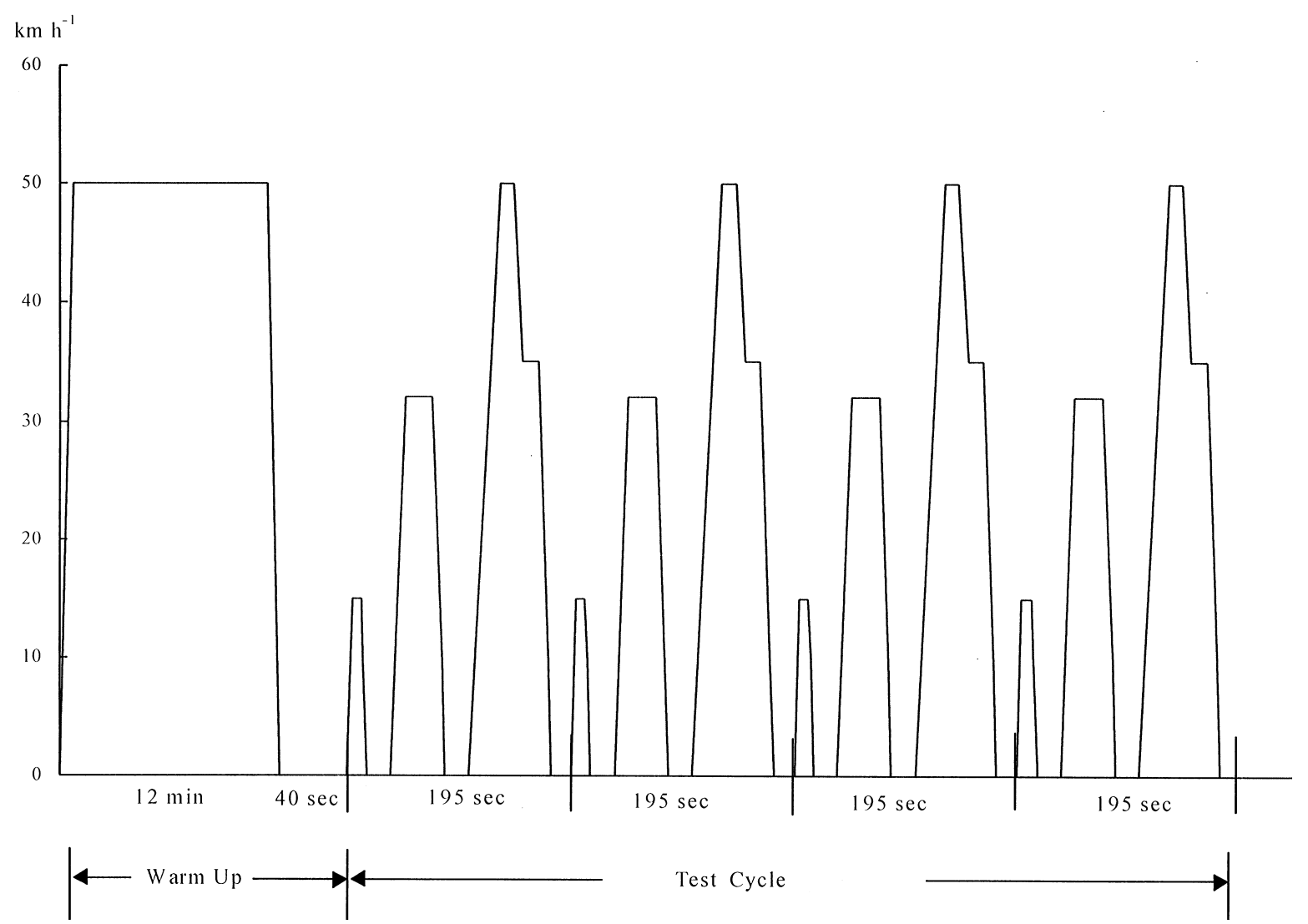

Fig. 1. ECE driving cycle of vehicle testing procedure.

Hewlett Packard 5972). The thermal desorber was preheated at $200^{\circ} \mathrm{C}$ and the injection temperature was $225^{\circ} \mathrm{C}$; the samples were standby at $35^{\circ} \mathrm{C}$ and the trap was cooled down to $-170^{\circ} \mathrm{C}$. Cryo was standby at $200^{\circ} \mathrm{C}$, the focus temperature was $-170^{\circ} \mathrm{C}$, and the MS line temperature was $200^{\circ} \mathrm{C}$. GC was equipped with a fused silica capillary column $(60 \mathrm{~m}$ at $0.32 \mathrm{~mm}$ ID with $1 \mu \mathrm{m}$ DB-1).

Calibration standard gases of hydrocarbon species were prepared by diluting the certified standard gas (56 Environ-Mat Ozone Precursor, 16183, Matheson) with ultra-high-purity nitrogen in dilution bottles. The performance of GC/MS was evaluated with perfluorotributylamine for quality control. The sum of those nonmethane hydrocarbon species was determined afterwards.

\subsection{Data analysis}

The emission factors of various pollutants were assessed with the exhaust concentrations, the volume of the exhaust, and the total running mileage in one test cycle. Because the actual exhaust volumes in various driving patterns were not available, the mean rotating speed of engine, volume of the cylinder, and the running time in that driving period were applied to derive the emission factors. The equations are listed as follows:

$E=M \times V^{*} \times 10^{-3}$,

$E F=E / L$,

where $E$ is the exhaust amount of the pollutant $(\mathrm{g})$ in a specific driving mode, $M$ is the concentration of the pollutant $\left(\mathrm{mg} \mathrm{N} \mathrm{m}^{-3}\right), V^{*}$ is the normalized value of the exhaust gas volume given by the dynamometer laboratory of the motorcycle manufacture plant after temperature and pressure correction $\left(\mathrm{Nm}^{3}\right), L$ is the traveled mileage during the test procedure $(\mathrm{km})$, and finally $\mathrm{EF}$ is the emission factor of that pollutant $\left(\mathrm{g} \mathrm{km}^{-1}\right)$.

\section{Results and discussion}

\subsection{Emission factors}

The emission factors for various pollutants are listed in Table 2. Except for $\mathrm{NO}_{x}$, the emission factors of $\mathrm{CO}$, 


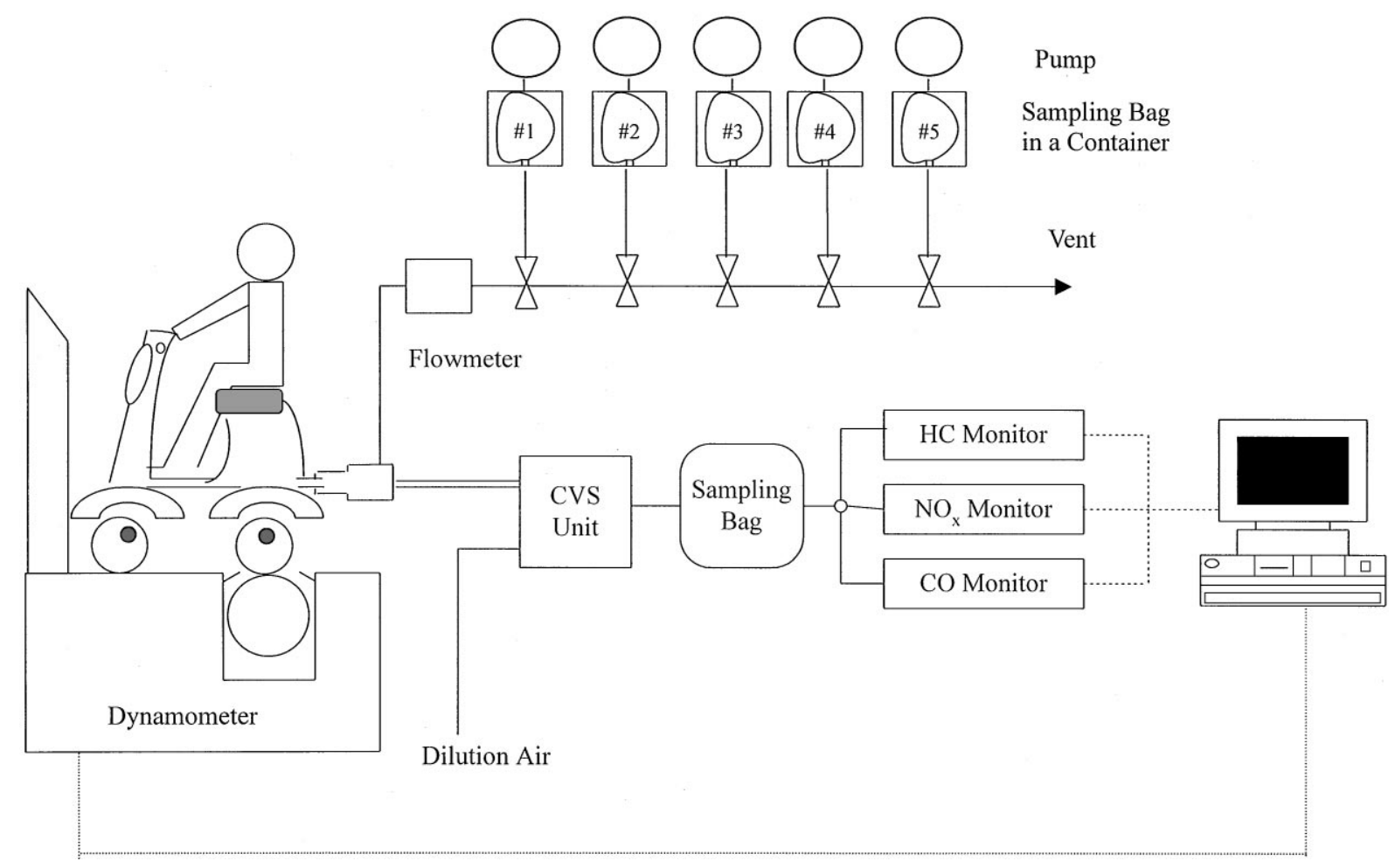

Fig. 2. Schematic diagram of gas sampling system.

Table 2

Emission factors of different type motorcycles

\begin{tabular}{llcccc}
\hline Motorcycle type & & \multicolumn{2}{l}{ Emission factors $\left(\mathrm{g} \mathrm{km}^{-1}\right)$} & & \\
\cline { 3 - 6 } & & $\mathrm{CO}$ & $\mathrm{NO}_{x}$ & THC & VOCs \\
\hline \multirow{2}{*}{ 2-stroke } & New-w-catalyst & $2.63 \pm 1.96$ & $0.035 \pm 0.035$ & $3.28 \pm 2.01$ & $2.59 \pm 2.43$ \\
& In-use-w-catalyst & $21.72 \pm 13.86$ & $0.016 \pm 0.006$ & $15.16 \pm 12.36$ & $5.17 \pm 3.70$ \\
& In-use-w/o-catalyst & $39.92 \pm 27.18$ & $0.015 \pm 0.003$ & $20.04 \pm 10.29$ & $7.89 \pm 6.37$ \\
4-stroke & New-w/o-catalyst & $5.66 \pm 0.76$ & $0.46 \pm 0.040$ & $1.50 \pm 1.49$ & $0.15 \pm 0.065$ \\
& In-use-w/o-catalyst & $36.10 \pm 13.58$ & $0.25 \pm 0.13$ & $3.20 \pm 0.56$ & $2.22 \pm 0.81$ \\
\hline
\end{tabular}

THC, and VOCs from in-use motorcycles are all higher than those from new ones. The most substantial differences occur in $\mathrm{CO}$ : the emission factor of in-use motorcycles is approximately $8-15$ times higher than the new ones of 2-stroke engine and 6 times than that of 4-stroke engine. In-use motorcycles also contribute more THC per kilometer than the new ones, especially for 2-stroke ones (4-6 times more). In addition, 2-stroke engines emitted more THC per kilometer traveled than 4-stroke ones, especially for the used motorcycles. The results obtained in this study are comparable to those of others
(Chan et al., 1995). These data indicate that the motorcycles equipped with catalyst significantly reduce $\mathrm{CO}$ and THC emissions. Summary from above results and statistics of Ministry of Transportation (1998), 2-stroke motorcycles are the dominant emission source of THCs in Taiwan.

In contrast, the $\mathrm{NO}_{x}$ emission factors of 4-stroke motorcycles are much higher than 2-stroke ones. However, the emission standard of $\mathrm{NO}_{x}$ for in-use motorcycle is not yet regulated in Taiwan. High combustion efficiency of fuel, may reduce emissions of hydrocarbon and $\mathrm{CO}$, 
but increase emission of $\mathrm{NO}_{x}$. These effects may explain the difference between 2- and 4-stroke engine emissions.

\subsection{Emission vs. engine mileage and catalyst converter installation}

The relationship between accumulated running mileage of the in-use motorcycles and various pollutant emissions show a slight correlation but great variation. For in-use 2-stroke motorcycles, the emission factors of $\mathrm{CO}$ and THC for those without catalyst are 1.84 and 1.32 times of those with catalyst, respectively. Installation of catalyst could effectively reduce emissions of $\mathrm{CO}$ and THC, but not for $\mathrm{NO}_{x}$. However, the emissions of $\mathrm{CO}$ and THC from in-use 2-stroke motorcycles without catalyst are 15.2 and 6.1 times of those from brand new 2-stroke motorcycles. The effective lifetime of catalyst is typically only 1-2 years, thus two-year or longer used motorcycles may perform as those without catalyst installation, unless those catalysts are replaced by new ones. Therefore, the status of catalyst can be very important to the emission degradation of THC and $\mathrm{CO}$ from 2-stroke motorcycles. In general, the emissions of $\mathrm{CO}$ and THC increase with the engine age. This trend is consistent with the study of Winebrake and Deaton (1997) in investigating the positive relationship between $\mathrm{HC}$ emissions and the age of the vehicle. Interesting enough, the $\mathrm{NO}_{x}$ emissions of in-use 2-stroke engines are not correlated with the installation of catalyst. In fact, new 2-stroke motorcycles with catalyst have higher $\mathrm{NO}_{x}$ emission than in-use 2-stroke motorcycles regardless of installation of catalyst or not. New motorcycles may perform better combustion efficiency and lead higher $\mathrm{NO}_{x}$ emissions.

\subsection{VOC groups in the tailpipe exhaust}

The concentrations of individual volatile organic compounds in the tailpipe exhaust were list in Table 3. There are totally 48 species of volatile organic compounds identified and quantified. Some species carried in the standard gas could not be found in the exhaust gas.

For new 2-stroke motorcycles, the dominant VOC species in the tailpipe exhaust include isopantane, $n$ pentane, toluene, 2-methylpentane, and 3-methylpentane. For in-use 2-stroke motorcycles, the dominant species are isopentane, toluence, 2-methylpentane, $n$-pentane and $m, p$-xylene, which are similar to new 2-stroke motorcycle exhaust.

The dominant species of VOCs in the exhaust from new 4-stroke motorcycle are toluence, isopentane, propylene, $n$-pentane, and $m, p$-xylene. The concentrations of the other species are usually lower than $20 \mathrm{mg} \mathrm{N} \mathrm{m}^{-3}$. The dominant species of VOCs in the exhaust from in-use 4-stroke motorcycle are toluene, isopentane, $m, p$ xylene, $n$-pentane, and $o$-xylene, with concentrations beyond $200 \mathrm{mg} \mathrm{N} \mathrm{m}^{-3}$.

The prevalently dominant VOCs species in the exhaust from various types of motorcycles include isopentane, $n$-pentane, and toluene, while $m, p$-xylene is also a dominant component among VOC speciation in the engine exhaust. The data shown in Table 3 also indicate that the VOCs profiles in the motorcycle exhaust from are very complicated. However, the profile of VOCs in the engine exhausts is anticipated to be affected by fuel composition, engine combustion condition, and pollution control device equipped.

Totally 47 species of volatile organic compounds in the tailpipe exhaust were identified and grouped into three categories: alkane (24 species), alkene (13 species), and aromatics (10 species), while 9 remaining components of standard gas were not detected in the exhausts. The molecule weight of these species are in the range between ethylene $(\mathrm{MW}=28.05)$ and $n$-nonane $(\mathrm{MW}=128.26)$, which include benzene, toluene, xylene, and trimethylbenzene. The mass fractions of various VOC species from 2- and 4-stroke engines were not consistent. The concentrations of various species from new and in-use motorcycles were also varied a little. Table 4 indicates the mass fractions of three VOC groups based upon values of the emission factors.

Aromatic VOCs is the dominant group both for new and in-use 4-stroke engines. Alkane VOCs is the dominant group for 2-stroke engines. The mass fraction of aromatic VOCs in new and in-use 4-stroke motorcycles did not change significantly, but the mass fraction varied in 2-stroke motorcycle emissions. The changes of alkane and alkene between in-use and new motorcycles were obvious. The mass fraction of alkane reduced for in-use 2-stroke motorcycles while those of alkene and aromatic species increased significantly as compared to new ones. On the contrary, the mass fraction of alkane slightly increased for in-use 4-stroke engines while those of alkene decreased in the engine exhaust.

\subsection{VOCs emission from various driving pattern}

The emission factors of total 47 VOCs at various driving modes on the dynamometer are listed in Table 5. For 2-stroke motorcycles, the emission during the deceleration mode is the highest among all driving modes both for the in-use and the new motorcycles. The installation of the catalyst significantly reduces VOC emission. For used 4-stroke motorcycles, the emission during the deceleration mode is also the highest. In all cases the emission factors of VOCs in the $50 \mathrm{~km} \mathrm{~h}^{-1}$ cruising mode is higher than those in $30 \mathrm{~km} \mathrm{~h}^{-1}$ mode. These results are different from that reported by Sigsby et al. (1987), who suggested a less hydrocarbon emissions with a higher cruising speed. 
Table 3

Mass concentrations $\left(\mathrm{mg} \mathrm{Nm}^{-3}\right)$ of VOCs from motorcycle exhaust ${ }^{\mathrm{a}}$

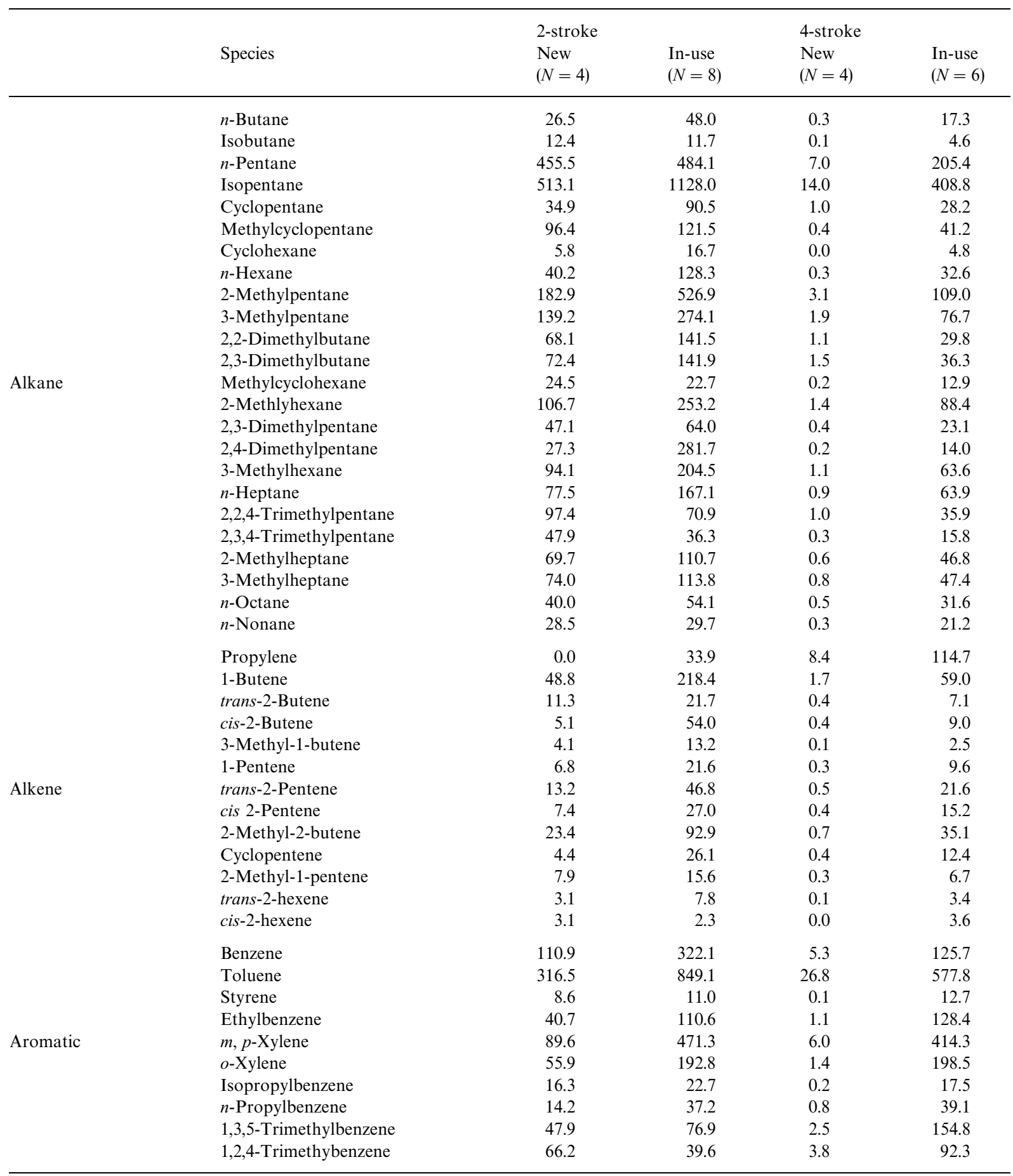

${ }^{\mathrm{a}} N$ : Number of samples. 
Table 4

Mass fractions (based upon emission factors) of three VOC groups

\begin{tabular}{|c|c|c|c|c|c|}
\hline \multirow[t]{2}{*}{ Motorcycle type } & & \multirow[t]{2}{*}{ Number } & \multicolumn{3}{|c|}{ VOC mass fraction $(\%)$} \\
\hline & & & Alkane & Alkene & Aromatic \\
\hline \multirow[t]{3}{*}{ 2-stroke } & New-w-catalyst & 4 & $69 \pm 4$ & $5 \pm 1$ & $26 \pm 3$ \\
\hline & In-use-w-catalyst & 5 & $57 \pm 20$ & $11 \pm 7$ & $32 \pm 15$ \\
\hline & In-use-w/o-catalyst & 3 & $45 \pm 6$ & $16 \pm 16$ & $39 \pm 22$ \\
\hline \multirow[t]{2}{*}{ 4-stroke } & New-w/o-catalyst & 3 & $40 \pm 11$ & $13 \pm 5$ & $47 \pm 6$ \\
\hline & In-use-w/o-catalyst & 4 & $44 \pm 12$ & $10 \pm 5$ & $46 \pm 17$ \\
\hline
\end{tabular}

Table 5

Emissions of VOCs from motorcycle exhaust at different driving patterns

\begin{tabular}{|c|c|c|c|c|c|c|}
\hline \multirow{2}{*}{$\begin{array}{l}\text { Motorcycle } \\
\text { type }\end{array}$} & & \multicolumn{5}{|c|}{ Emission factors $\left(\mathrm{g} \mathrm{km}^{-1}\right)$} \\
\hline & & Idle & Acceleration & $30 \mathrm{~km} \mathrm{~h}^{-1}$ cruise & $50 \mathrm{~km} \mathrm{~h}^{-1}$ cruise & Deceleration \\
\hline \multirow{3}{*}{ 2-stroke } & New-w-catalyst & $0.98 \pm 0.99$ & $1.24 \pm 0.47$ & $1.60 \pm 1.88$ & $2.78 \pm 2.52$ & $4.13 \pm 4.40$ \\
\hline & In-use-w-catalyst & $0.98 \pm 0.82$ & $2.27 \pm 1.28$ & $2.23 \pm 1.32$ & $3.11 \pm 0.97$ & $4.41 \pm 3.52$ \\
\hline & In-use-w/o-catalyst & $2.11 \pm 1.42$ & $2.81 \pm 2.23$ & $5.20 \pm 6.15$ & $6.54 \pm 6.94$ & $13.39 \pm 11.21$ \\
\hline \multirow[t]{3}{*}{ 4-stroke } & New-w/o-catalyst & $0.01 \pm 0.01$ & $0.16 \pm 0.14$ & $0.07 \pm 0.05$ & $0.23 \pm 0.21$ & $0.16 \pm 0.04$ \\
\hline & In-use-w/o-catalyst & $0.32 \pm 0.28$ & $0.47 \pm 0.39$ & $0.54 \pm 0.46$ & $0.83 \pm 0.59$ & $3.58 \pm 1.69$ \\
\hline & & \multicolumn{5}{|c|}{ Mass emissions (g test-mode ${ }^{-1}$ ) } \\
\hline \multirow[t]{3}{*}{ 2-stroke } & New-w-catalyst & $3.92 \pm 4.00$ & $1.18 \pm 0.43$ & $2.29 \pm 2.53$ & $1.85 \pm 1.70$ & $3.49 \pm 3.79$ \\
\hline & In-use-w-catalyst & $3.92 \pm 3.48$ & $2.17 \pm 1.26$ & $3.21 \pm 1.92$ & $2.07 \pm 0.62$ & $3.73 \pm 2.80$ \\
\hline & In-use-w/o-catalyst & $8.44 \pm 5.72$ & $2.68 \pm 2.11$ & $7.47 \pm 8.50$ & $4.36 \pm 4.86$ & $11.31 \pm 9.42$ \\
\hline \multirow[t]{2}{*}{ 4-stroke } & New-w/o-catalyst & $0.04 \pm 0.04$ & $0.15 \pm 0.14$ & $0.10 \pm 0.07$ & $0.15 \pm 0.14$ & $0.14 \pm 0.04$ \\
\hline & In-use-w/o-catalyst & $1.28 \pm 1.16$ & $0.45 \pm 0.38$ & $0.78 \pm 0.65$ & $0.56 \pm 0.39$ & $3.02 \pm 1.62$ \\
\hline
\end{tabular}

The total emissions of VOCs in a test cycle to simulate the on-road emission fraction for various driving modes are also shown in Table 5. For in-use 2-stroke motorcycles with catalyst, the emissions from idle and deceleration modes contribute about $50 \%$ of total emission of the test cycle, and $57 \%$ of those without catalyst. The data strongly support the policy to phase out the 2stroke motorcycles in the near future for THC emission reduction in Taiwan. However, the type shift of motorcycles from 2- to 4-stroke will increase the emission of $\mathrm{NO}_{x}$ in the source category of motorcycles.

\section{Conclusions}

The emissions of CO, THC, and some species of VOCs from in-use motorcycles are higher than those from new ones as tested on a dynamometer. The emission factors of THC from 2-stroke motorcycles, either with or without catalyst installation, are higher than that from 4-stroke motorcycles without catalyst. The emissions of $\mathrm{CO}$ for in-use motorcycles are much higher than new engines, no matter whether installation of catalyst or not. It also shows a clear degradation of $\mathrm{CO}$ emissions for inuse motorcycles. However, installation of catalyst on 2-stroke motorcycles could significantly reduce the emission of $\mathrm{CO}$ and THC, but not the $\mathrm{NO}_{x}$ emission. The effect of accumulated running mileage and engine age on the emissions of $\mathrm{CO}$ and THC show a slight correlation but great variation. The results indicate that a number of factors, such as maintenance, may play an important role in engine emission from motorcycles.

\section{Acknowledgements}

This study is supported by grants from Taiwan Environmental Protection Administration (EPA-87FA42-13-F5) and National Science Council (NSC-882211-E-006-069). Professor Oliver J. Hao's remarkable suggestion on the preparations of this paper is appreciated. The authors also are grateful to Dr. Shih-Chun Lung for her assistance in this study.

\section{References}

Chan, C.C., Nien, C.K., Tsai, C.Y., Her, G.R., 1995. Comparison of tail-pipe emissions from motorcycle and passenger cars. Journal of Air and Waste Management Association 45, 116-124. 
MOT, 1998. Monthly Report of Traffic Affairs. Ministry of Transportation, Taiwan, Republic of China.

Sigsby, J., Tejada, S., Ray, W., Lang, J.M., Duncan, J.W., 1987. Volatile organic emissions from 46 in-use passenger cars. Environmental Science and Technology 21, 466-475.

TEPA, 1996. The Driving Pattern and Emission Estimation of Vehicle in Taipei Metropolitan Area. Environmental Protection Administration, Taiwan, Republic of China.

TEPA, 1997. State of the Environment. Environmental Protection Administration, Taiwan.
TEPA, 1998. Emission of Air Pollutants from the Mobile Sources in Taiwan. Environmental Protection Administration, Taiwan, Republic of China.

Tsai, J.H., Liang, C.P., Lee, D.Z., Hsu, Y.C., Lin, S.J., 1997. Characteristic of airborne volatile aromatics in Tainan, Taiwan. Journal of Environmental Engineering ASCE 23, 406-409.

Winebrake, J.J., Deaton, M.L., 1997. A comparative analysis of emissions deterioration for in-use alternative fuel vehicles. Journal of Air and Waste Management Association 47, 1291-1296. 